\title{
The Implementation of a Visco-hyperelastic Numerical Material Model for Simulating the Behaviour of Polymer Foam Materials
}

Conor Briody

Technological University Dublin, conor.briody@tudublin.ie

Barry Duignan

Technological University Dublin, Barry.Duignan@tudublin.ie

Stephen Jerrams

Technological University Dublin, stephen.jerrams@tudublin.ie

See next page for additional authors

Follow this and additional works at: https://arrow.tudublin.ie/cerart

Part of the Computational Engineering Commons, and the Polymer and Organic Materials Commons

\section{Recommended Citation}

Briody, C., Duignan, B., Jerrams, S. \& Tiernan, J. (2012) The Implementation of a Visco-hyperelastic Numerical Material Model for Simulating the Behaviour of Polymer Foam Materials. Journal of Computational Material Science. 2012. doi:10.1016/j.commatsci.2012.04.012

This Article is brought to you for free and open access by the Centre for Elastomer Research at ARROW@TU Dublin. It has been accepted for inclusion in Articles by an authorized administrator of ARROW@TU Dublin. For more information, please contact arrow.admin@tudublin.ie, aisling.coyne@tudublin.ie,gerard.connolly@tudublin.ie. Funder: ABBEST 


\section{Authors}

Conor Briody, Barry Duignan, Stephen Jerrams, and John Tiernan

This article is available at ARROW@TU Dublin: https://arrow.tudublin.ie/cerart/10 


\title{
The implementation of a visco-hyperelastic numerical material model for simulating the behaviour of polymer foam materials
}

\author{
Conor Briody ${ }^{\mathrm{a}, *}$, Barry Duignan ${ }^{\mathrm{a}}$, Steve Jerrams ${ }^{\mathrm{a}}$, John Tiernan ${ }^{\mathrm{b}}$ \\ ${ }^{a}$ Dublin Institute of Technology, Bolton St., Dublin 1, Ireland \\ ${ }^{\mathrm{b}}$ SeatTech, Enable Ireland, Sandymount, Dublin 4, Ireland
}

\section{A R T I C L E I N F O}

\section{Article history:}

Received 2 November 2011

Received in revised form 30 March 2012

Accepted 4 April 2012

Available online $\mathrm{xxxx}$

\section{Keywords:}

Polyurethane foam

Indentation

Hyperelastic

Viscoelastic

Modelling

Finite Element

\begin{abstract}
A B S T R A C T
Polyurethane foam has been in use for some time in wheelchair seating systems as it offers good pressure relieving capabilities in most cases. However, little characterisation work has gone into seating foam materials by comparison with conventional elastomeric materials. Accurate material models could allow better prediction of foam in-service behaviour, which could potentially improve seating design practises. The objective of this work was to develop an approach for the validation of hyperelastic and viscoelastic material model parameters used to simulate polyurethane foam behaviour. Material parameters were identified from relevant test procedures and implemented in a Finite Element simulation of an ISO foam indentation procedure. Physical test results were compared to results predicted using the identified material parameters. Simulations suggest a good overall agreement between test and model results.
\end{abstract}

(C) 2012 Elsevier B.V. All rights reserved.

\section{Introduction}

Increased understanding of polyurethane foam used in wheelchair seating can enable superior design and enhanced pressure distribution, potentially leading to improved comfort and support.

Polyurethane foam is an open celled elastomeric polymer. Its constituent elastomer (polyurethane rubber) can undergo large and reversible elastic deformations. Usually, cellular materials like polyurethane foam exhibit three regions of different stress-strain behaviour in uni-axial compression. These regions are (i) approximately linear behaviour for strains less than about 0.05 , due to the bending of cell edges, (ii) a plateau region where strain increases at nearly constant stress up to a strain of approximately 0.6 , due to elastic buckling of the cell edges and (iii) a densification region where the stress-strain curve increases exponentially as collapsed cell edges come into contact with each other, causing the material behaviour to approach that of the bulk polymer [1].

Polyurethane foams also exhibit viscoelasticity [2,3], the material's modulus depends on material temperature and the timescale of the applied load. In wheelchair seating applications, this allows the material to conform to body shape over time, increasing cushion contact area with the body and improving pressure distribution.

A non-linear material model is required to simulate deformation of polyurethane foam. The Ogden Hyperfoam model is avail-

\footnotetext{
* Corresponding author. Tel.: +353 (0)1 4022982.

E-mail address: conor.briody@dit.ie (C. Briody).
}

able in several Finite Element (FE) programmes and has been used by a number of authors. Research by Mills et al. used the Ogden model to simulate different applications including running shoe soles and crash helmets [4-7]. Grujicic et al. [8] used the Ogden model to represent foam in auto seat-passenger models. Viscoelasticity was not accounted for in the models presented in these papers.

\section{Material testing}

Material tests were conducted on samples from a batch of opencelled polyurethane foam. The material had a density of $40 \mathrm{~kg} / \mathrm{m}^{3}$ and is widely used in wheelchair seating applications. Uni-axial and shear test results were used to identify numerical material model parameters for the Ogden Hyperfoam model. Stress relaxation test results were used to develop parameters for a Prony series, which was used to allow for the inclusion of viscoelastic material behaviour. Indentation Force Deflection (IFD) testing was also conducted for the purpose of material model validation.

\subsection{Test methods}

All testing was based on International Standards Organisation (ISO) standards [9-13]. Axial compression testing was undertaken on foam samples with dimensions of $150 \mathrm{~mm} \pm 1 \mathrm{~mm}$ length by $150 \mathrm{~mm} \pm 1 \mathrm{~mm}$ breadth by $50 \mathrm{~mm}$ height and each sample was conditioned at the testing temperature of $23 \pm 2{ }^{\circ} \mathrm{C}$ for $16 \mathrm{~h}$ prior 


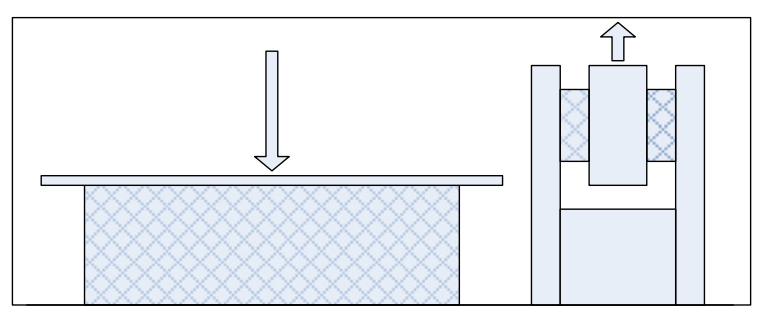

Fig. 1. Schematic of uni-axial (left) and simple shear (right) test set-ups (not to scale), chequered area represents foam.

to testing [16]. The test-piece was inserted centrally between two horizontal platens attached to a Lloyds testing machine (LR30K), fitted with a $2.5 \mathrm{kN}$ load cell. A $0.5 \mathrm{~N}$ preload was applied to the test-piece and was retained on it when the specimen was fully decompressed. This ensured that the test-piece would not loosen on decompression in repeated test cycles. For the first test, the sample was compressed to a strain of 0.7 at a strain rate of $71.4 \times 10^{-5} / \mathrm{s}$ (corresponding to a crosshead feed rate of $5 \mathrm{~mm} /$ $\mathrm{min}$ ), and then decompressed at the same strain rate. This cycle was repeated immediately three times and on the fourth compression cycle, load-deflection data was recorded. The initial three cycles on the virgin foam sample were applied to reduce the Mullins effect [14].

The stress relaxation test procedure measured the decrease in counterforce exerted by a test-piece of polymer foam compressed to a constant deformation at a temperature of $23 \pm 2{ }^{\circ} \mathrm{C}$. Samples were compressed to a strain of 0.8 at a strain rate of $71.4 \times 10^{-3} /$ $\mathrm{s}$ and held for $8 \mathrm{~h}$. This time was chosen to replicate a typical daily occupancy of a wheelchair user. Reaction force was monitored throughout the test.

A dual-lap testing rig, similar to that developed by Siriruk et al. [15] for testing in simple shear, was designed and constructed. Simple shear foam test samples had the following dimensions: $6 \mathrm{~mm}$ thickness, $20 \mathrm{~mm}$ width and $25 \mathrm{~mm}$ length. Test-piece size complied strictly to standards as shear modulus is dimension sensitive [16]. Samples were bonded, using cyanoacrylate adhesive on both sides, to rigid plates during testing. Tests were conducted at a shear strain rate of $26.7 \times 10^{-4} / \mathrm{s}$ until failure (see Fig. 1 ).

\subsection{Material model validation testing using rigid loading}

Indentation Force Deflection tests were conducted using a flat cylindrical indenter. The indenter shape was a scaled down version of the standard IFD indenter. The indenter was axially indented into the foam samples at strain rates of $71.4 \times 10^{-5} / \mathrm{s}$ and $71.4 \times 10^{-4} / \mathrm{s}$ to a strain of 0.7 using the Lloyds testing machine. After each loading, the indenter was held at a 0.7 strain for a period of $8 \mathrm{~h}$.

\section{Material model parameter identification}

\subsection{Hyperelastic material modelling}

Uni-axial compression data sets were obtained (Section 2.1) and were used to identify material parameters for a 2nd order Ogden Hyperfoam material model [17,18], Eq. (1):

$U=\sum_{i=1}^{N} \frac{2 \mu_{i}}{\alpha_{i}^{2}}\left[\hat{\lambda}_{1}^{\alpha_{i}}+\hat{\lambda}_{2}^{\alpha_{i}}+\hat{\lambda}_{3}^{\alpha_{i}}-3+\frac{1}{\beta_{i}}\left(\left(J^{e l}\right)^{-\alpha_{i} \beta_{i}}-1\right)\right]$

where $U$ is the strain energy per unit volume, $N$ is the order of fitting, $\mu_{i}, \alpha_{i}$, and $\beta_{i}$ are temperature-dependent material parameter and $\hat{\lambda}_{i}$ represents principal stretch ratios:
$\hat{\lambda}_{i}=\left(J_{t h}\right)^{-\frac{1}{3}} \rightarrow \hat{\lambda}_{1} \hat{\lambda}_{2} \hat{\lambda}_{3}=J^{e l}$

where $J^{e l}$ is the elastic volume ratio and $J_{t h}$ is the thermal volume ratio, defined in Eq. (3):

$J^{e l}=\frac{J}{J_{t h}}$

where $J$ is the total volume ratio.

The transverse stretches, $\lambda_{1}$ and $\lambda_{3}$, were negligible during the uni-axial compression test, suggesting that an assumption of Poisson's ratio $v=0$ was valid. This has been assumed by others modelling similar foam materials $[3,8,19]$. Eq. (1) can thus be simplified to allow calculation of the nominal stress, $T_{2}$ in the $\lambda_{2}$ load direction using the following equation:

$T_{2}=\frac{\partial U}{\partial \lambda_{2}}=\frac{2}{\lambda_{2}} \sum_{i=1}^{N} \frac{\mu_{i}}{\alpha_{i}}\left[\lambda_{2}^{\alpha_{i}}-J_{e l}^{-\alpha_{i} \beta_{i}}\right]$

Parameter $\beta_{i}$ can be calculated using the following equation:

$\beta_{i}=\frac{v_{i}}{1-2 v_{i}}$

and since $v_{i}=0, \beta_{i}=0$. The $\mu_{i}, \alpha_{i}$, and $\beta_{i}$ parameters satisfied the Drucker stability criterion [18]. Only the loading curve was considered when evaluating the material parameters for the material model.

Simple shear test data (Section 2.1), was curve-fitted to generate a more robust material model for complex material behaviour simulation. Simple shear data was calculated using Eq. (6):

$T_{S}=\frac{\partial U}{\partial \gamma}=\sum_{j=1}^{2}\left[\frac{2 \gamma}{2\left(\lambda_{j}^{2}-1\right)-\gamma^{2}} \sum_{i=1}^{N} \frac{\mu_{i}}{\alpha_{i}}\left(\lambda_{j}^{\alpha_{i}}-1\right)\right]$

where $\gamma$ is the shear strain, $\lambda_{1}$ and $\lambda_{2}$ are the two principal stretches in the plane of shearing and are related to shear strain by:

$\lambda_{1,2}=\sqrt{1+\frac{\gamma^{2}}{2} \pm \gamma \sqrt{1+\frac{\gamma^{2}}{4}}}$

Least squares optimisation was used to determine the $\mu_{i}$ and $\alpha_{i}$ parameters for the uni-axial data set alone, the shear data set alone and finally using both data sets simultaneously. The uni-axial model alone provides accurate results when modelling a uni-axial compression procedure (Fig. 2).

However the parameters are completely unstable when attempting to model shear. Fig. 3 depicts the different models' accuracies when modelling a shear deformation. The parameters

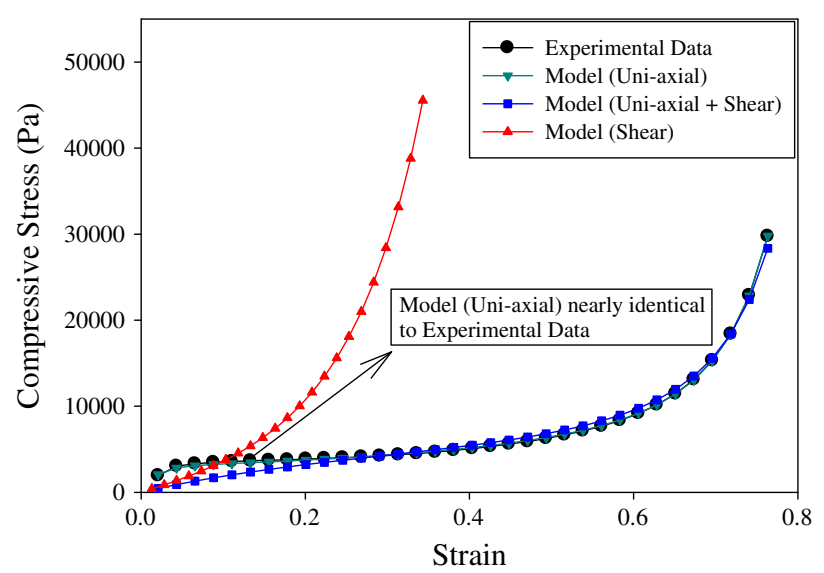

Fig. 2. Uni-axial compression data for sample compressed to a strain of 0.78 at a strain rate of $71.4 \times 10^{-4} / \mathrm{s}$ at $23^{\circ} \mathrm{C}$ compared with an Ogden Hyperfoam model curve-fit for the uni-axial, combination and shear cases. 
generated from simultaneously fitting test datasets from uni-axial compression and shear tests (see Table 1), gave a model with better overall stability when compared with parameters fitted from either dataset alone (see Figs. 2 and 3).

\subsection{Modelling viscoelastic behaviour}

Viscoelastic phenomena such as creep and stress relaxation were prominent in tests. The relaxation (Young's) modulus, $E(t)$, was measured during the uni-axial stress relaxation procedure. The normalised relaxation modulus data was modelled as a number of Maxwell elements connected in parallel with a single spring element. This system can be represented mathematically using a Prony series:

$E(t)=\left(E_{\infty}+\sum_{i=1}^{N} E_{k} e^{\left(-t / \tau_{k}\right)}\right)$

where $E_{k}$ is the relaxation magnitude and $\tau_{k}$ is the relaxation time. Both are material dependent properties. The long term response is represented by $E_{\infty}$ and $N$ is the order of the Prony series. A 4 th order Prony series was fitted to the normalised stress relaxation test data, with parameters identified using a least squares optimisation technique. An 8th order Prony series which provided a more accurate curve fit, parameters displayed in Table 2, was then fitted to the test data. Both models are compared to normalised stress relaxation data in Fig. 4. The 8th order model is capable of predicting stress relaxation, creep and strain rate variance of the polyurethane foam for a given strain and strain rate. The parameters of this model are chosen for use in all simulations. Relaxation modulus was noted as being dependent on strain. In this study one level of strain was chosen (0.7), which was considered most relevant to the intended application.

The Prony series parameters (Table 2) were implemented in conjunction with the Ogden Hyperfoam model parameters (Table 1), to simulate material behaviour in the simulations described in Section 4. Eq. (9) alters the $\mu_{i}$ Ogden parameters to include time dependent viscoelastic behaviour using the relaxation moduli, $E_{k}$ and $\tau_{k}$ :

$\mu_{i}^{R}(t)=\mu_{i}^{0}\left(1-\sum_{k=1}^{N} E_{k}\left(1-e^{-t / \tau_{k}}\right)\right)$

where $\mu_{i}^{o}$ is the original hyperfoam material parameter and $\mu_{i}^{R}$ is the relaxed hyperfoam material parameter.

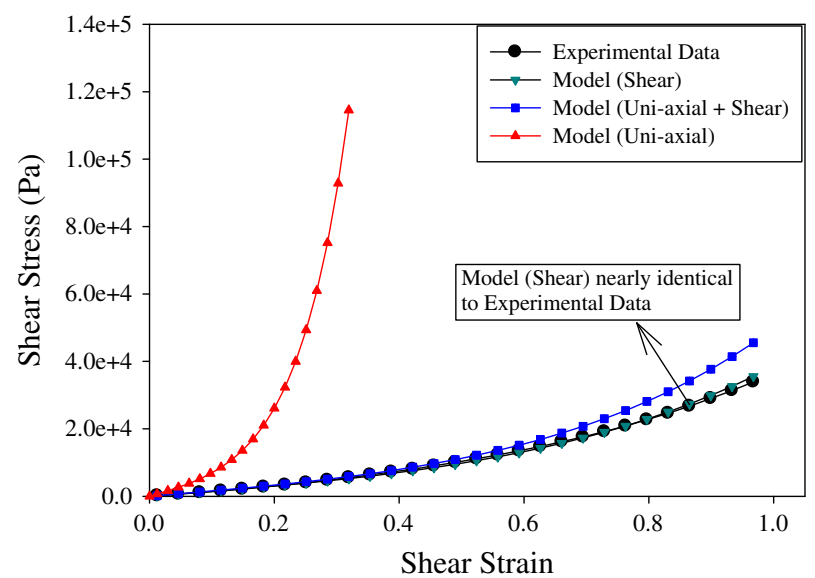

Fig. 3. Simple shear data for sample sheared to a strain of 1 at a shear strain rate of $26.7 \times 10^{-4} / \mathrm{s}$ compared with an Ogden Hyperfoam model curve-fit for the shear, combination and uni-axial cases.
Table 1

Ogden Hyperfoam model parameters.

\begin{tabular}{llll}
\hline$N$ & $\mu_{i}(\mathrm{~Pa})$ & $\alpha_{i}$ & $\beta_{i}$ \\
\hline 1 & $1.27 \mathrm{E}+04$ & $7.28 \mathrm{E}+00$ & $0.00 \mathrm{E}+00$ \\
2 & $2.75 \mathrm{E}+00$ & $-5.73 \mathrm{E}+00$ & $0.00 \mathrm{E}+00$
\end{tabular}

Table 2

Prony series parameters.

\begin{tabular}{lrl}
\hline$N$ & \multicolumn{1}{c}{$E_{k}$} & $\tau_{k}(\mathrm{~s})$ \\
\hline 1 & $6.17 \mathrm{E}-04$ & $1.01 \mathrm{E}-03$ \\
2 & $-1.27 \mathrm{E}-03$ & $1.89 \mathrm{E}-03$ \\
3 & $8.99 \mathrm{E}-02$ & $2.93 \mathrm{E}-01$ \\
4 & $1.15 \mathrm{E}-01$ & $4.74 \mathrm{E}+00$ \\
5 & $8.03 \mathrm{E}-02$ & $5.52 \mathrm{E}+01$ \\
6 & $7.72 \mathrm{E}-02$ & $6.30 \mathrm{E}+02$ \\
7 & $6.86 \mathrm{E}-02$ & $8.66 \mathrm{E}+03$ \\
8 & $-3.01 \mathrm{E}-02$ & $1.74 \mathrm{E}+08$ \\
\hline
\end{tabular}

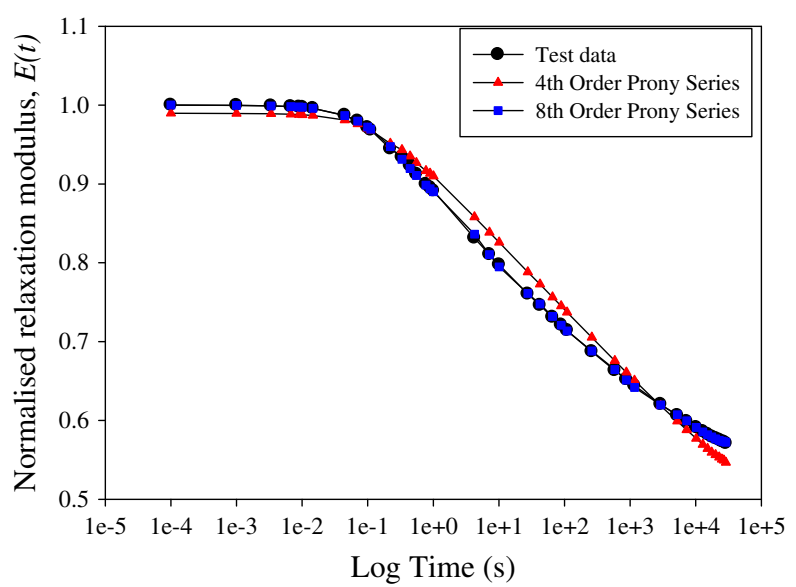

Fig. 4. Normalised stress relaxation test data for sample strained at $71.4 \times 10^{-3} / \mathrm{s}$ to a strain of 0.7 and held for $8 \mathrm{~h}$, compared with 4 th and 8 th order mathematical Prony series representations.

\section{FE simulation of IFD test}

The IFD indentation was simulated using Abaqus FE package. The indenter (Fig. 5) and the base were modelled as metal with a Young's Modulus of $200 \times 10^{9} \mathrm{~N} / \mathrm{m}^{2}$ and a Poisson's ratio of 0.3 . The cushion foam material was modelled as described in Section 3. All of the model was meshed with eight-node brick elements. Penalty contact surface-surface algorithms were imposed at all material interfaces. A quarter-symmetry model, displayed in Fig. 6, was solved using the reduced integration elements offered by Abaqus.

A coefficient of friction of 0.75 was assumed $[19,20]$. The method was applied to model the interactions between the foam and

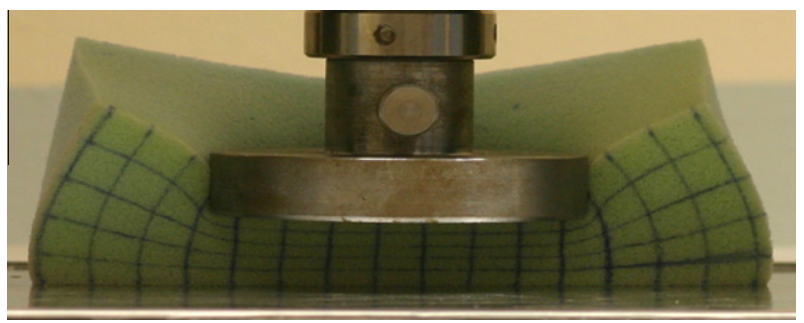

Fig. 5. IFD test set-up. 


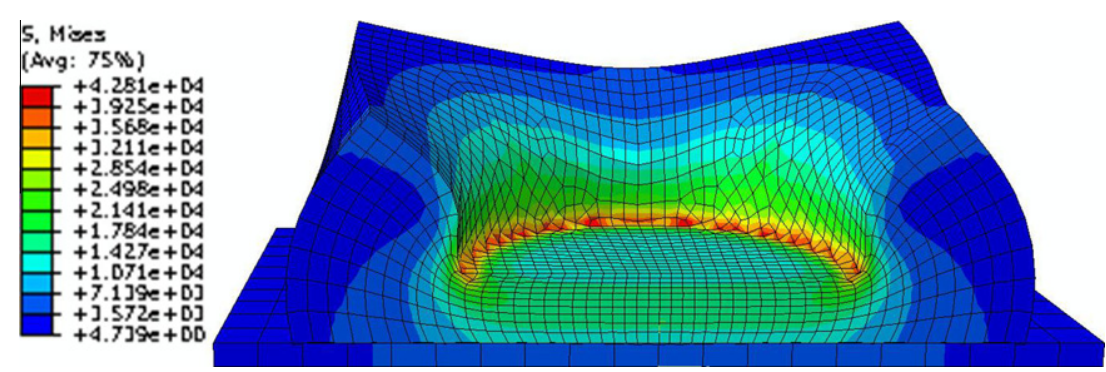

Fig. 6. Meshed IFD simulation set-up.

the indenter. The model simulated indentations at strain rates of $71.4 \times 10^{-5} / \mathrm{s}$ and $71.4 \times 10^{-4} / \mathrm{s}$. Each indentation was followed by an $8 \mathrm{~h}$ dwell period. This mimicked the behaviour of the forced indenter.

\section{Results and validation}

Element deformation patterns from the front edge of the simulated foam, Fig. 6, were similar to that of the grid deformation patterns from the deformed foam sample in Fig. 5. In Figs. 7 and 8, force-time data from IFD tests at strain rates of $71.4 \times 10^{-5} / \mathrm{s}$ and $71.4 \times 10^{-4} / \mathrm{s}$ respectively, were compared with indenter reaction forces predicted by the viscoelastic model throughout the $8 \mathrm{~h} \mathrm{sim}$ ulation period. Results from a hyperfoam model without viscoelasticity (no time dependent relaxation), are provided for comparison with the viscoelastic model. The higher strain rate model predicted higher peak force. The highest force values represent the end of the load stage and the beginning of the relaxation period.

The Ogden Hyperfoam model represents material behaviour throughout the load stage and is capable of predicting peak forces accurately.

The Prony series parameters are responsible for the relaxation behaviour of the material model. The overall shape of the relaxation curve provided by the model is appropriate, however some discrepancies are noticeable throughout the relaxation period. Fig. 7 shows that after the load period, the $71.4 \times 10^{-5} / \mathrm{s}$ strain rate viscoelastic model begins to diverge slightly from test results. The divergence remains constant in the 4-6\% range throughout the relaxation period. The maximum divergence for the $71.4 \times 10^{-4} / \mathrm{s}$ strain rate viscoelastic model (Fig. 8) occurs in the initial stages, with the model being $10.6 \%$ lower than the test results after $60 \mathrm{~s}$, reducing to $4 \%$ after $600 \mathrm{~s}$.

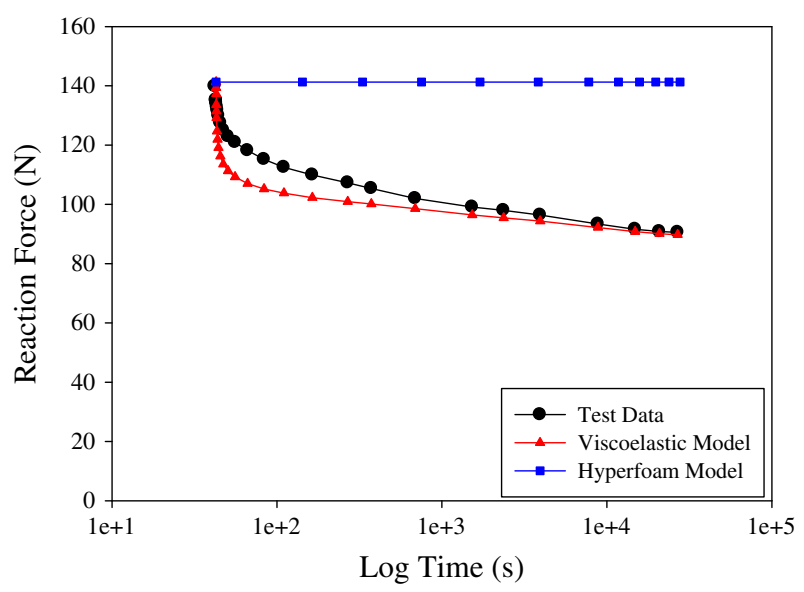

Fig. 7. Stress relaxation of sample indented at a strain rate of $71.4 \times 10^{-5} / \mathrm{s}$ to a strain of 0.7 by an IFD indenter compared with viscoelastic model predictions.

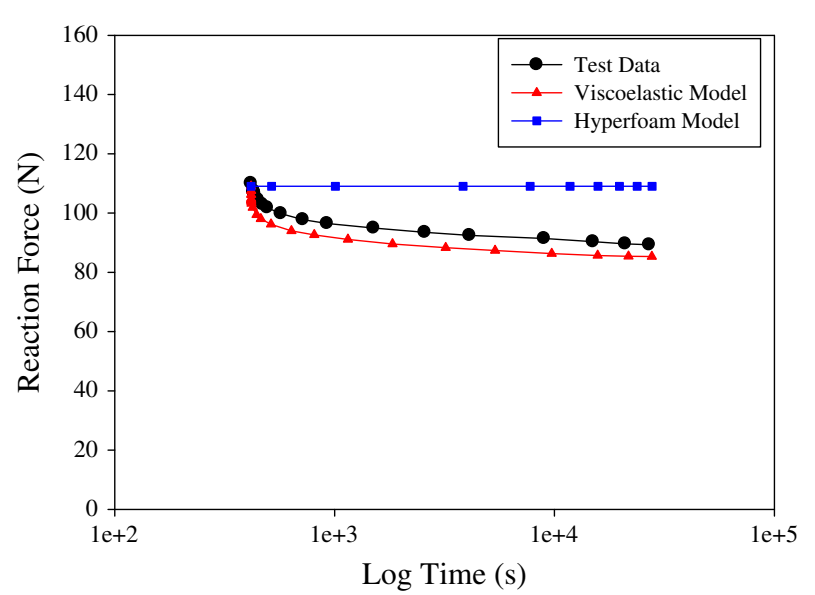

Fig. 8. Stress relaxation of a sample indented at a strain rate of $71.4 \times 10^{-4} / \mathrm{s}$ to a strain of 0.7 by an IFD indenter compared with viscoelastic model predictions.

There are some discrepancies between the viscoelastic model and test results. Sample inhomogoneity and small differences in sample size meant the IFD procedure was only repeatable to within $\pm 5 \%$. Implementation of this model when simulating an axial loadrelaxation procedure results in good correlation (maximum error $<5 \%$ ) between model and test results. This error may have been increased with the introduction of the IFD indenter which created more complex strain patterns. Discrepancies may occur when attempting to simulate this complex material behaviour using the material model, especially the material in tension adjacent to the outside edge of the indenter.

Overall the model compared well with the indentation procedure, indicating that the model was capable of complex indentation simulation over extended time periods.

\section{Conclusions}

A 2nd order Ogden compressible hyperelastic material model with viscoelastic effects included was developed with material parameters determined from uni-axial, shear and stress relaxation tests. The material model was validated by its implementation in a FE simulation of an indentation procedure. Physical test results were compared with simulation results using a viscoelastic enabled model and a non-viscoelastic model. There was good general agreement between test data and the viscoelastic model. Some improvements in model accuracy may be achieved by testing fully homogenous samples in a wider range of deformation modes.

The validation procedure presented here provides an outline for the development of suitable polyurethane foam material model parameters. Future work will include further material model development and verification, including the modelling of tempera- 
ture dependence providing more realistic simulations of foam behaviour in applications such as seating.

\section{Acknowledgments}

The authors thank Enable Ireland (SeatTech) for donating foam samples and technical support, the Irish Centre for High End Computing (ICHEC) and the DIT ABBEST postgraduate scheme.

\section{References}

[1] L.J. Gibson, M.F. Ashby, Cellular Solids-Structures and Properties, second ed. Cambridge University Press, 1997.

[2] I.M.S.J. Ward, An Introduction to the Mechanical Properties of Solid Polymers, vol. 2, Wiley, 2004.

[3] N. Mills, Polymer Foams Handbook, Elsevier, Oxford, 2007.

[4] N.J. Mills, C. Fitzgerald, A. Gilchrist, R. Verdejo, Composites Science and Technology 63 (2003) 2389-2400.

[5] N.J.M.G. Lyn, Sports Engineering 4 (2001) 153-163.

[6] N.G.A. Mills, Cellular Polymers 19 (2000) 389-412.

[7] N.J. Mills, G. Lyn, Materials in Sports and Science (2001) 105-117.
[8] M. Grujicic, B. Pandurangan, G. Arakere, W.C. Bell, T. He, X. Xie, Materials and Design 30 (2009) 4273-4285.

[9] ISO:3386, Polymeric Materials, Cellular Flexible - Determination of StressStrain Characteristic in Compression, ISO, 2010.

[10] ISO:2439, Flexible Cellular Polymeric Materials - Determination of Hardness (Indentation Technique), ISO, 2008.

[11] ISO:1827, Rubber, Vulcanized or Thermoplastic - Determination of Modulus in Shear, ISO, 2007.

[12] ISO:16840-2, Wheelchair Seating - Part 2: Determination of Physical and Mechanical Characteristics of Devices Intended to Manage Tissue Integrity Seat Cushions, ISO, 2007.

[13] ISO3384:2005, Rubber, Vulcanized or Thermoplastic - Determination of Stress Relaxation in Compression - Part 1: Testing at Constant Temperature, ISO, 2005.

[14] L. Mullins, Rubber Chemistry and Technology 42 (1969) 339-362.

[15] A. Siriruk, Y. Jack Weitsman, D. Penumadu, Composites Science and Technology 69 (2009) 814-820.

[16] A. Wada, T. Kawasaki, Y. Minoda, A. Kataoka, S. Tashiro, H. Fukuda, Composite Structures 60 (2003) 385-390.

[17] R.W. Ogden, Proceedings of the Royal Society of London. A. Mathematical and Physical Sciences 328 (1972) 567-583.

[18] Simulia, Analysis User's Manual, Abaqus/CAE, vol. 6.1, 2010.

[19] N. Mills, A. Gilchrist, Cellular Polymers 19 (2000) 389-412.

[20] M. Schrodt, G. Benderoth, A. Kühhorn, G. Silber, Technische Mechanik 25 (2005) 162-173. 